\title{
Refractometric Studies on Molecular Interactions in Six Binary Liquid Mixtures
}

\author{
Nizamul Haque Ansari ${ }^{1}$, Anand Trivedi ${ }^{2}$, Dhirendra Kumar Sharma ${ }^{3}$, Prakash Chandra ${ }^{3^{*}}$ \\ ${ }^{1}$ Department of Chemistry, Rajdhani College, University of Delhi, New Delhi, India \\ ${ }^{2}$ Department of Chemistry, SRIT College, Datia, India \\ ${ }^{3}$ Department of Chemistry, Bundelkhand University, Jhansi, India \\ Email: drprakashcy@gmail.com
}

Received October 23, 2013; revised November 20, 2013; accepted November 28, 2013

Copyright (c) 2014 Nizamul Haque Ansari et al. This is an open access article distributed under the Creative Commons Attribution License, which permits unrestricted use, distribution, and reproduction in any medium, provided the original work is properly cited. In accordance of the Creative Commons Attribution License all Copyrights (C) 2014 are reserved for SCIRP and the owner of the intellectual property Nizamul Haque Ansari et al. All Copyright (C 2014 are guarded by law and by SCIRP as a guardian.

\begin{abstract}
Refractive indices of the six binary mixtures between N-Butyl bromide with Aniline, Benzene, Xylene, Carbon tetrachloride, n-Heptane and Toluene for the entire concentration range have been measured at $303.15 \mathrm{~K}$. Furthermore, deviation in refractive indices from ideal mixture, molar refraction, deviation in molar refraction from ideal values for these mixtures has also been evaluated. The results are discussed in term of molecular interactions between the components of the binary mixtures.
\end{abstract}

\section{KEYWORDS}

\section{Refractive Indices; Density; Molecular Interactions; Molar Refraction; Lorentz-Lorenz Relation}

\section{Introduction}

The studies of refractive indices are being increasingly used as tools [1-5] for investigation of the physical properties of pure components and the nature of intermolecular interaction between the liquid mixture constituents. Refractive index measurements of binary liquid mixtures are essential for determination of composition of binary mixtures usually for non-ideal mixtures where experimental measurements are performed directly over the entire range of composition. The review of literature [6] on acoustical studies of solution reveals that refractive indices measurements are also used to estimate the different elastic properties of the molecule from which the type of molecular interactions can be very well understood. Pandey et al. [7] have made refractive indices measurements in liquid mixtures and have suggested that such studies are very much helpful for understanding of the molecular interactions in the components of the mixture. In addition to binary liquid mixtures, a few ternary, $[8,9]$ mixtures have also been studied employing refractive index measurements. However, literature survey shows that study of molecular interactions between $\mathrm{N}$ -

*Corresponding author.
Butyl bromide and hydrocarbon molecules either by refractive index measurements or other methods is rare. Taking these into considerations, in the present study we have reported refractive index data for binary mixture of N-Butyl bromide with Aniline, Benzene, Xylene, Carbon tetrachloride, n-Heptane and Toluene for the entire concentration range.

\section{Experimental}

\section{Materials and Methods}

Six binary systems, viz N-Butyl bromide + Aniline, NButyl bromide + Benzene, N-Butyl bromide + Xylene, $\mathrm{N}$-Butyl bromide + Carbon tetrachloride. N-Butyl bromide + n-heptane and N-Butyl bromide + Toluene, were studied. All chemicals were of Rankem Ltd. (AR grade, 98\% - 99\% pure) chemicals were purified by fractional distillation method [10]. Binary mixtures of N-Butyl bromide + Aniline, N-Butyl bromide + Benzene, N-Butyl bromide + Xylene, N-Butyl bromide + Carbon tetrachloride. $\mathrm{N}$-Butyl bromide $+\mathrm{n}$-heptane and $\mathrm{N}$-Butyl bromide + Toluene, were prepared by weight covering the entire mole fraction range. The components of binary mixtures 
were injected by means of syringe in to the glass vials of sealed with rubber stopper in order to check evaporation losses during sample preparation. Refractive indices of pure liquids and liquid mixtures were measured using white light by an Abbe refract meter (Model R-8 M/S Mittal Enterprised, New Delhi) Refract meter was calibrated with kept constant at $303.15 \mathrm{~K} \pm 0.03 \mathrm{~K}$ by circulating water of the thermostat with the help of pump through both the prism boxes of the refract meter. Refractive indices of liquid were measured after attainment of constant temperature. An average of five measurements was made for each sample. Density of pure liquids and liquid mixtures at experimental temperature were determined using double steam capillary type pyknometer. Pyknometer was also calibrated with liquids of known density values. The weight of the sample was measured using electrical single pan analytical balance (K-Roy).

\section{Results and Discussion}

The experimental values of refractive indices $\left(n_{\text {mix }}\right)$ and density $\left(\rho_{\text {mix }}\right)$ at $303.15 \mathrm{~K}$ with mole fraction of second components for all binary mixtures of N-Butyl bromide and second components are reported in Table 1. Values of deviation in refractive indices $(\Delta n)$ for all the systems studied are evaluated using experimental values of refractive indices for pure liquids and liquid mixtures employing following equation [11] (Equation (1))

$$
\Delta n=n_{\text {mix }}-n_{\text {ideal }}
$$

where $n_{\text {mix }}$ and $n_{\text {ideal }}$ are refractive indices of actual binary mixture and ideal binary mixtures.

The refractive index deviation, $\Delta n$, has been calculated on a molefraction basis and $n_{\text {ideal }}$ has been evaluated by Equation (2).

$$
n_{\text {ideal }}=X_{1} n_{1}+X_{2} n_{2}
$$

where $X_{1}, X_{2}$ and $n_{1}, n_{2}$ are the mole fraction and refractive indices of the components 1 and 2 respectively. Values of deviation in refractive indices, $\Delta n$, with compositions of the binary mixtures studied at experimental temperature are also recorded in Table 1.

The experimental values of refractive indices and densities of the mixtures have been used to evaluated molar refraction, $R$, employing Lorentz-Lorenz equation,

$$
R=V_{\text {mix }}\left(n_{\text {mix }}^{2}-1\right) /\left(n_{\text {mix }}^{2}+2\right)
$$

where $V_{\text {mix }}\left[=\left(X_{1} M_{1}+X_{2} M_{2}\right) / \rho_{\text {mix }}\right]$ is the molar volume of the mixtures. Deviation in molar refraction, $\Delta R$ is evaluated by Equation (4),

$$
\Delta R=R_{\text {mix }}-R_{\text {ideal }}
$$

where

$$
R_{\text {ideal }}=X_{1} R_{1}+X_{2} R_{2}
$$

The value of molar refraction and $\Delta R$ are recorded in Table 1. Perusal of Table 1 shows that experimental refractive indices decrease with mole fraction of N-Butyl bromide increases, for the binary mixtures of all the N-Butyl bromide with Aniline, Benzene, Xylene, Carbon tetrachloride, n-Heptane and Toluene, except that refractive indices increases with mole fraction of N-Butyl bromide increases in type system N-Butyl bromide + n-heptane. Values of $\Delta n$ for the entire composition range of N-Butyl bromide in binary mixture of the Aniline, Benzene, Xylene, Carbon tetrachloride, n-Heptane and Toluene, are negative.

On the basis of the above, it seems that molecular interactions play an important role in governing the deviation in refractive indices for the binary systems studied in the present investigation. It may also be concluded that there is a gradual change in molecular interactions between the components of binary mixtures. Values of molar refraction, $R$, evaluated by Equation (3) and deviations in molar refractions, $\Delta R$ at experimental temperature for all binary mixtures are reported in Table 1. perusal of Table 1 shows that for binary mixtures of different hydrocarbon and $\mathrm{CCl}_{4}$ with a common N-Butyl bromide, $R$, values have the following trend in the entire composition range, Benzene $<$ carbon tetrachloride $<$ Aniline $<$ Toluene $<$ Xylene $<$ n-Heptane.

The above order shows the graded interactions between components of the mixtures. Since R can be interpreted as a hard-core volume of one mole of molecules, its values have been associated with atoms, groups of atoms and even types of chemical bonds [12]. Fermeglia and Torriano [13] define deviation in molar refraction on mole fraction basis while it is defined on the basis of volume fraction [14] by others. Herein, we have reported $\Delta R$ values on the mole fraction basis. Table 1 shows that $\Delta R$ values for all the systems studied are negative $[15,16]$. It may be concluded that the interactions resulting in the interstitial accommodation of benzene in to Toluene are the predominant factor over dipole-dipole and dipole induced-dipole interaction.

\section{Conclusions}

The present investigations show that the interactions resulting in the interstitial accommodation of benzene into Toluene are the predominant factor over dipole-dipole and dipole induced-dipole interaction between the unlike molecules. The existence of molecular interaction in the mixture is in the order: Benzene $<$ carbon tetrachloride $<$ Aniline $<$ Toluene $<$ Xylene $<$ n-Heptane. It may also be concluded that there is a gradual change in molecular interactions between the components of binary mixtures. The values of deviation in molar refraction for all the systems studied are negative. 
Table 1. Mole fraction $\left(x_{1}\right)$, densities $\left(\rho_{\text {mix }}\right)$, refractive indices $\left(n_{\text {mix }}\right)$, deviation in refractive indices $(\Delta n)$, molar refraction $\left(R_{\text {mix }}\right)$ and deviation in molar refraction $(\Delta R)$ for different binary mixtures at $303.15 \mathrm{~K}$.

N-Butyl bromide $\left(\mathrm{X}_{1}\right)+$ Aniline $\left(\mathrm{X}_{2}\right)$

\begin{tabular}{|c|c|c|c|c|c|}
\hline $\mathrm{X}_{1}$ & $\rho_{\text {mix }}\left(10^{3} \mathrm{kgm}^{-3}\right)$ & $\mathrm{n}_{\text {mix }}$ & $\Delta \mathrm{n}$ & $\mathrm{R}_{\text {mix }}$ & $\Delta \mathrm{R}$ \\
\hline 0.0000 & 1.0071 & 1.6200 & & 32.4829 & \\
\hline 0.0979 & 1.0432 & 1.6050 & -0.0016 & 32.4036 & -0.2178 \\
\hline 0.1961 & 1.0814 & 1.5920 & -0.0013 & 32.3634 & -0.4469 \\
\hline 0.2811 & 1.0894 & 1.5800 & -0.0018 & 32.2200 & -0.0228 \\
\hline 0.3981 & 1.1206 & 1.5650 & -0.0010 & 32.1502 & -0.1587 \\
\hline 0.5006 & 1.1404 & 1.5510 & -0.0012 & 32.1032 & -0.2291 \\
\hline 0.5976 & 1.1597 & 1.5370 & -0.0021 & 32.0839 & -0.2684 \\
\hline 0.6955 & 1.1878 & 1.5220 & -0.0039 & 31.7525 & -0.0235 \\
\hline 0.7990 & 1.2050 & 1.5090 & -0.0029 & 31.5736 & -0.0973 \\
\hline 0.8957 & 1.2410 & 1.4970 & -0.0019 & 31.2292 & -0.3433 \\
\hline 1.0000 & 1.2481 & 1.4850 & & 31.4665 & \\
\hline \multicolumn{6}{|c|}{ N-Butyl bromide $\left(\mathrm{X}_{1}\right)+$ Benzene $\left(\mathrm{X}_{2}\right)$} \\
\hline $\mathbf{X}_{1}$ & $\rho_{\text {mix }}\left(10^{3} \mathrm{kgm}^{-3}\right)$ & $\mathrm{n}_{\text {mix }}$ & $\Delta \mathrm{n}$ & $\mathrm{R}_{\text {mix }}$ & $\Delta \mathrm{R}$ \\
\hline 0.0000 & 0.8659 & 1.5410 & & 28.3460 & \\
\hline 0.0970 & 0.9193 & 1.5340 & -0.0014 & 28.3437 & -0.3050 \\
\hline 0.1998 & 0.9632 & 1.5260 & -0.0036 & 28.6430 & -0.3265 \\
\hline 0.2964 & 1.0051 & 1.5170 & -0.0072 & 28.7676 & -0.5033 \\
\hline 0.3969 & 1.0385 & 1.5090 & -0.0096 & 29.1816 & -0.4030 \\
\hline 0.4625 & 1.0913 & 1.5070 & -0.0079 & 29.2562 & -0.5328 \\
\hline 0.5961 & 1.1222 & 1.5040 & -0.0034 & 29.8780 & -0.3281 \\
\hline 0.6872 & 1.1304 & 1.4980 & -0.0043 & 30.7537 & -0.2633 \\
\hline 0.7994 & 1.1861 & 1.4930 & -0.0030 & 30.8097 & -0.1608 \\
\hline 0.8993 & 1.2220 & 1.4880 & -0.0024 & 30.9091 & -0.2431 \\
\hline 1.0000 & 1.2481 & 1.4850 & & 31.4665 & \\
\hline \multicolumn{6}{|c|}{ N-Butyl bromide $\left(\mathrm{X}_{1}\right)+$ Xylene $\left(\mathrm{X}_{2}\right)$} \\
\hline $\mathrm{X}_{1}$ & $\rho_{\text {mix }}\left(10^{3} \mathrm{kgm}^{-3}\right)$ & $\mathrm{n}_{\text {mix }}$ & $\Delta \mathrm{n}$ & $\mathrm{R}_{\text {mix }}$ & $\Delta \mathrm{R}$ \\
\hline 0.0000 & 0.8518 & 1.5380 & & 38.9865 & \\
\hline 0.1000 & 0.8914 & 1.5340 & -0.0014 & 38.0988 & -0.1358 \\
\hline 0.1971 & 0.9292 & 1.5290 & -0.0016 & 37.2582 & -0.2461 \\
\hline 0.2971 & 0.9658 & 1.5230 & -0.0020 & 36.4815 & -0.2708 \\
\hline 0.2631 & 1.0017 & 1.5180 & -0.0059 & 34.5741 & -0.4264 \\
\hline 0.4976 & 1.0427 & 1.5120 & -0.0005 & 34.4633 & -0.7812 \\
\hline 0.5986 & 1.0820 & 1.5050 & -0.0011 & 34.1680 & -0.3169 \\
\hline 0.6994 & 1.1244 & 1.4990 & -0.0017 & 33.3608 & -0.3662 \\
\hline 0.7938 & 1.1669 & 1.4930 & -0.0027 & 32.5434 & -0.4737 \\
\hline 0.8948 & 1.2064 & 1.4860 & -0.0042 & 31.8385 & -0.4191 \\
\hline 1.0000 & 1.2481 & 1.4850 & & 31.4665 & \\
\hline
\end{tabular}




\section{Continued}

N-Butyl bromide $\left(\mathrm{X}_{1}\right)+$ Carbon tetrachloride $\left(\mathrm{X}_{2}\right)$

\begin{tabular}{|c|c|c|c|c|c|}
\hline $\mathrm{X}_{1}$ & $\rho_{\text {mix }}\left(10^{3} \mathrm{kgm}^{-3}\right)$ & $\mathrm{n}_{\text {mix }}$ & $\Delta \mathrm{n}$ & $\mathrm{R}_{\text {mix }}$ & $\Delta \mathrm{R}$ \\
\hline 0.0000 & 1.5662 & 1.5010 & & 28.9349 & \\
\hline 0.0980 & 1.5464 & 1.4980 & -0.0012 & 28.9647 & -0.3384 \\
\hline 0.1992 & 1.5050 & 1.4960 & -0.0018 & 29.2075 & -0.2317 \\
\hline 0.2970 & 1.4715 & 1.4950 & -0.0010 & 29.4959 & -0.1909 \\
\hline 0.3861 & 1.4464 & 1.4930 & -0.0016 & 29.6044 & -0.3079 \\
\hline 0.4954 & 1.4079 & 1.4910 & -0.0019 & 29.9310 & -0.2581 \\
\hline 0.5970 & 1.3694 & 1.4900 & -0.0012 & 30.3592 & -0.0871 \\
\hline 0.6949 & 1.3390 & 1.4880 & -0.0017 & 30.5875 & -0.1069 \\
\hline 0.7993 & 1.3076 & 1.4870 & -0.0010 & 30.8809 & -0.0775 \\
\hline 0.8922 & 1.2832 & 1.4860 & -0.0015 & 31.0643 & -0.1293 \\
\hline 1.0000 & 1.2481 & 1.4850 & & 31.4665 & \\
\hline \multicolumn{6}{|c|}{ N-Butyl bromide $\left(\mathrm{X}_{1}\right)+\mathrm{n}$-Heptane $\left(\mathrm{X}_{2}\right)$} \\
\hline $\mathrm{X}_{1}$ & $\rho_{\text {mix }}\left(10^{3} \mathrm{kgm}^{-3}\right)$ & $\mathrm{n}_{\text {mix }}$ & $\Delta \mathrm{n}$ & $\mathrm{R}_{\text {mix }}$ & $\Delta \mathrm{R}$ \\
\hline 0.0000 & 0.6713 & 1.4380 & & 39.1128 & \\
\hline 00.0957 & 0.7145 & 1.4360 & -0.0018 & 3708975 & -0.4835 \\
\hline 0.2005 & 0.7654 & 1.4310 & -0.0022 & 36.3348 & -1.2449 \\
\hline 0.3003 & 0.8131 & 1.4406 & -0.0024 & 36.0219 & -0.7947 \\
\hline 0.3976 & 0.8705 & 1.4510 & -0.0025 & 35.4889 & -0.5838 \\
\hline 0.5015 & 0.9216 & 1.4540 & -0.0049 & 34.8438 & -0.4343 \\
\hline 0.5968 & 0.9818 & 1.4590 & -0.0048 & 33.9999 & -0.5496 \\
\hline 0.7012 & 1.0443 & 1.4630 & -0.0060 & 33.2238 & -0.5274 \\
\hline 0.7981 & 1.1096 & 1.4680 & -0.0063 & 32.4576 & -0.5527 \\
\hline 0.8993 & 1.1770 & 1.4720 & -0.0070 & 31.7141 & -0.5224 \\
\hline 1.0000 & 1.2481 & 1.4850 & & 31.4665 & \\
\hline \multicolumn{6}{|c|}{ N-Butyl bromide $\left(\mathrm{X}_{1}\right)+$ Toluene $\left(\mathrm{X}_{2}\right)$} \\
\hline $\mathrm{X}_{1}$ & $\rho_{\text {mix }}\left(10^{3} \mathrm{kgm}^{-3}\right)$ & $\mathrm{n}_{\text {mix }}$ & $\Delta \mathrm{n}$ & $\mathrm{R}_{\text {mix }}$ & $\Delta \mathrm{R}$ \\
\hline 0.0000 & 0.8528 & 1.5380 & & 33.7949 & \\
\hline 0.0984 & 0.8986 & 1.5310 & -0.0016 & 33.2449 & -0.3209 \\
\hline 0.1980 & 0.9330 & 1.5260 & -0.0013 & 33.2371 & -0.0968 \\
\hline 0.2961 & 0.9757 & 1.5200 & -0.0021 & 32.8505 & -0.2549 \\
\hline 0.3936 & 1.0170 & 1.5150 & -0.0019 & 32.5595 & -0.3189 \\
\hline 0.4982 & 1.0539 & 1.5100 & -0.0014 & 32.4947 & -0.1402 \\
\hline 0.5968 & 1.0954 & 1.5050 & -0.0012 & 32.2033 & -0.2020 \\
\hline 0.6933 & 1.1354 & 1.5000 & -0.0011 & 31.9302 & -0.2504 \\
\hline 0.7945 & 1.1725 & 1.4930 & -0.0027 & 31.6787 & -0.2663 \\
\hline 0.8962 & 1.2156 & 1.4890 & -0.0013 & 31.4283 & -0.2799 \\
\hline 1.0000 & 1.2481 & 1.4850 & & 31.4665 & \\
\hline
\end{tabular}

\section{Acknowledgements}

This work has been carried out with financial assistance from UGC, New Delhi, (Grant No.33-493/2007(SR), dated 28.02.2008.

\section{REFERENCES}

[1] T. M. Aminabhavi, K. Banerjee and R. H. Balundgi, "Thermodynamic Interactions in Binary Mixtures of 1-
Chloronaphthalene and Monocyclic Aromatics,” Indian Journal of Chemistry, Vol. 38A, 1999, p. 768.

[2] A. Pal and A. Kumar, "Excess Molar Volumes, Viscosities, and Refractive Indices of Diethylene Glycol Dimethyl Ether with Dimethyl Carbonate, Diethyl Carbonate, and Propylene Carbonate at $(298.15,308.15$, and 318.15) K," Journal of Chemical \& Engineering Data, Vol. 43, No. 2, 1998, pp. 143-147. http://dx.doi.org/10.1021/je9701902

[3] A. H. Al-Dujali, A. A. Yassen and A. M. Awwad, "Re- 
fractive Indices, Densities, and Excess Properties of 4-(2Hydroxyethyl)morpholine + Water at (298.15, 308.15, and 318.15) K," Journal of Chemical \& Engineering Data, Vol. 45, No. 5, 2000, pp. 647-649. http://dx.doi.org/10.1021/je0000322

[4] A. K. Nain, P. Chandra, J. D. Pandey and S. Gopal, "Densities, Refractive Indices, and Excess Properties of Binary Mixtures of 1,4-Dioxane with Benzene, Toluene, o-Xylene, $m$-Xylene, $p$-Xylene, and Mesitylene at Temperatures from (288.15 to 318.15) K," Journal of Chemical \& Engineering Data, Vol. 53, No. 11, 2008, pp. 2654-2665. http://dx.doi.org/10.1021/je800579j

[5] A. K. Nain, "Molecular Interactions in Binary Mixtures of Formamide with 1-Butanol, 2-Butanol, 1,3-Butanediol and 1,4-Butanediol at Different Temperatures: An Ultrasonic and Viscometric Study," Fluid Phase Equilibria, Vol. 265, No. 46, 2008, p. 56.

[6] M. I. Aralaguppi, Jadar and T. M. Aminabhavi, "Density, Refractive Index, Viscosity, and Speed of Sound in Binary Mixtures of Cyclohexanone with Benzene, Methylbenzene, 1,4-Dimethylbenzene, 1,3,5-Trimethylbenzene, and Methoxybenzene in the Temperature Interval (298.15 to 308.15) K," Journal of Chemical \& Engineering Data, Vol. 44, No. 3, 1999, pp. 446-450. http://dx.doi.org/10.1021/je980219h

[7] J. D. Pandey, V. Vyas, G. P. Dubey, N. Tripathi and R. Dey, "Speed of Sound, Viscosity and Refractive Index of Multicomponent Systems: Theoretical Predictions from the Properties of Pure Components," Journal of Molecular Liquids, Vol. 81, 1999, pp. 123-133. http://dx.doi.org/10.1016/S0167-7322(99)00061-6

[8] J. A. Acosta, E. Rodil and A. Soto, "Density, Refractive Index, Viscosity, and Speed of Sound in Binary Mixtures of Cyclohexanone with Benzene, Methylbenzene, 1,4-Dimethylbenzene, 1,3,5-Trimethylbenzene, and Methoxybenzene in the Temperature Interval (298.15 to 308.15) K,” Journal of Chemical \& Engineering Data, Vol. 46, No. 5, 2001, pp. 1176-1180. http://dx.doi.org/10.1021/je0100490

[9] C. C. Wang, H. W. Chen and C. H. Tu, Densities, "Vis- cosities, and Refractive Indices for Binary and Ternary Mixtures of Ethanol, 2-Methylpropan-2-ol, and 2,2,4Trimethylpentane,” Journal of Chemical \& Engineering Data, Vol. 50, No. 5, 2005, pp. 1687-1693. http://dx.doi.org/10.1021/je0501639

[10] S. Kamila, V. Chakravarthy and S. Jena, "Studies on Acoustic Behavior, Viscosity, and Density of Some Commercial Extractants and Their Molecular Interaction with Diluent, Modifier, and Extractant," Journal of Solution Chemistry, Vol. 33, No. 4, 2004, pp. 365-380. http://dx.doi.org/10.1023/B:JOSL.0000036307.76436.a0

[11] S. S. Yadav, N. Kushwaha and N. Yadav, "Refractrometric Studies on Molecular Interactions between Some Bromoalkanes and Nonpolar Hydrocarbons,” Indian Journal of Chemistry, Vol. 48A, 2009, pp. 650-657.

[12] S. Glasstone, "Taxt book of Physical Chemistry,” Mac Millan India Limited, Delhi, 1997, Chapter 8.

[13] M. Fermeglia and G. Torriano, "Density, Viscosity, and Refractive Index for Binary Systems of $n$-C16 and Four Nonlinear Alkanes at 298.15 K," Journal of Chemical \& Engineering Data, Vol. 44, No. 5, 1999, p. 965-969. http://dx.doi.org/10.1021/je9900171

[14] M. I. Aralaguppi, T. M. Aminabhavi, R. H. Balundgi and S. S. Joshi, "Thermodynamic Interactions in Mixtures of Bromoform with Hydrocarbons," The Journal of Physical Chemistry, Vol. 95, No. 13, 1991, pp. 5299-5308. http://dx.doi.org/10.1021/j100166a070

[15] M. R. Riazi and Y. Roomi, "Use of the Refractive Index in the Estimation of Thermophysical Properties of Hydrocarbons and Petroleum Mixtures,” Industrial \& Engineering Chemistry Research, Vol. 40, No. 8, 2001, p. 1975.

[16] F. Comelli, S. Ottani, R. Francesconi and C. Castellar, "Densities, Viscosities, and Refractive Indices of Binary Mixtures Containing $n$-Hexane + Components of Pine Resins and Essential Oils at 298.15 K," Journal of Chemical \& Engineering Data, Vol. 47, No. 1, 2002, pp. 9397. http://dx.doi.org/10.1021/je010216w 